\title{
Leishmania interaction with an osteoclast
}

\author{
Flávio A. Naoum ${ }^{1,2}$ (10)
}

Received: 24 April 2019 / Accepted: 25 April 2019/Published online: 1 May 2019

(C) Springer-Verlag GmbH Germany, part of Springer Nature 2019

\begin{abstract}
Visceral leishmaniasis is caused by an intracellular protozoan parasite, Leishmania donovani. Frequently, a bone marrow aspirate can confirm the diagnosis by showing intracellular forms of Leishmania amastigotes in macrophages. Here we present a unusual interaction of Leishmania with an osteoclast in the bone marrow.
\end{abstract}

Keywords Leishmania $\cdot$ Bone marrow $\cdot$ Osteoclast $\cdot$ Macrophage

A 19-year old Brazillian female presented with a 2-month history of fatigue, weight loss, and daily fever. Physical examination revealed pallor and a moderately enlarged spleen. Her complete blood count results were as follows: hemoglobin, $8.5 \mathrm{~g} / \mathrm{dL}(12-16 \mathrm{~g} / \mathrm{dL})$; white cell count, $2.3 \times 10^{3} / \mu \mathrm{L}(4-$ $\left.10 \times 10^{3} / \mu \mathrm{L}\right)$; and platelet count, $80 \times 10^{3} / \mu \mathrm{L}(140-400 \times$ $\left.10^{3} / \mu \mathrm{L}\right)$. Serum protein electrophoresis showed hypergammaglobulinemia with a polyclonal gammopathy pattern. A bone marrow aspirate was performed and revealed a moderate erythroid hyperplasia and dyserythropoiesis, and showed intracellular forms of Leishmania amastigotes in macrophages and, unexpectedly, in an osteoclast (Fig. 1).

Visceral leishmaniasis is caused by an intracellular protozoan parasite, Leishmania donovani, transmitted by the bite of a female phlebotomine sandfly, and affects immunocompetent patients in endemic areas, such as South America [1]. Commonly, this parasitosis involves the mononuclear phagocytic system and the macrophages are the primary resident cell

Fig. 1 Bone marrow film showing Leishmania donovani bodies, with a paranuclear kinetoplast giving a characteristic "double-dot" appearance, in a macrophage (panel a) and in an osteoclast (panel b)

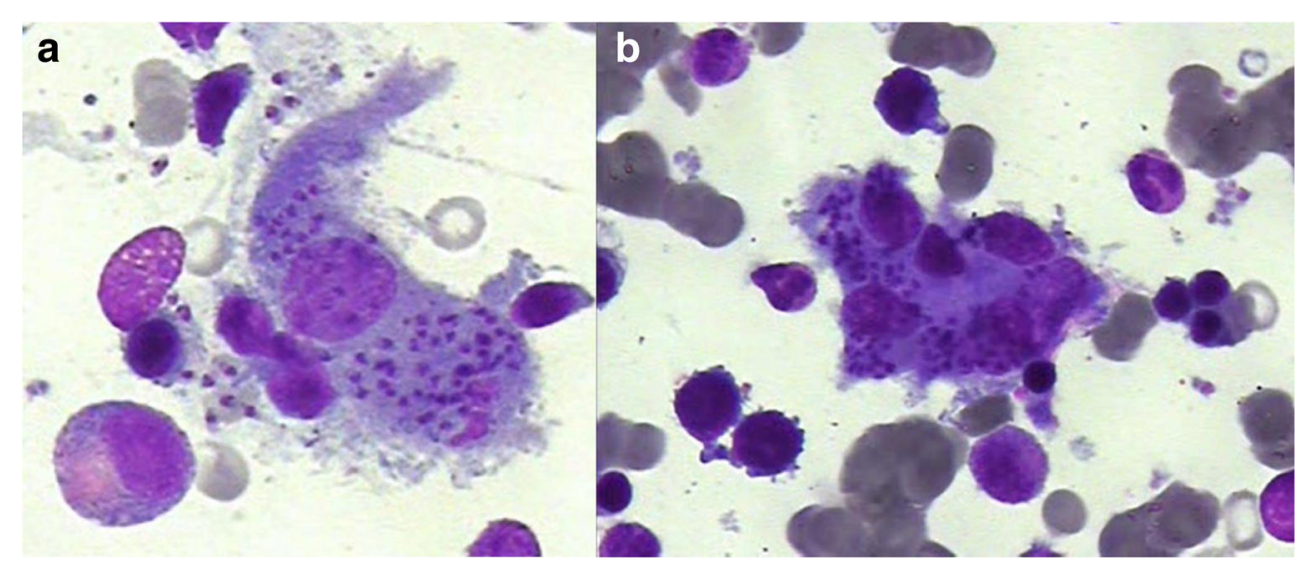

Flávio A. Naoum

drflavio@institutonaoum.com.br

1 Academia de Ciência e Tecnologia, Rua Bonfá Natale, 1860, São José do Rio Preto, São Paulo 15020130, Brazil

2 Faceres Medical School, São José do Rio Preto, São Paulo, Brazil for Leishmania [2]. Nevertheless, Leishmania donovani bodies were also reported in unusual locations such as myelocytes, plasma cells, and megakaryocytes [3]. In this patient, an uncommon and yet unreported interaction of Leishmania with an osteoclast was observed, which can be related to the fact that osteoclasts are derived from hematopoietic progenitors of the monocyte-macrophage lineage. 


\section{Compliance with ethical standards}

Conflict of interest The author declares that he has no conflict of interest.

\section{References}

1. Pace D (2014) Leishmaniasis. J Infect 69(Suppl 1):S10-S18

2. Sundar S, Rai M (2002) Laboratory diagnosis of visceral leishmaniasis. Clin Diagn Lab Immunol 9(5):951-958. https://doi.org/10. 1128/CDLI.9.5.951-958.2002
3. Kumar V, Agarwal P, Marwah S, Nigam AS, Tiwari A (2018) Spectrum of clinicohematological profile and its correlation with average parasite density in visceral leishmaniasis. Cytojournal 15 : 19. https://doi.org/10.4103/cytojournal.cytojournal_38_17

Publisher's note Springer Nature remains neutral with regard to jurisdictional claims in published maps and institutional affiliations. 